УДК 371.398

\title{
ПОДГОТОВКА К ШКОЛЕ С РОБОТАМИ: КОМПЛЕКСНАЯ МЕТОДИКА ДИАГНОСТИКИ И РАЗВИТИЯ НЕОБХОДИМЫХ ЗНАНИЙ, УМЕНИЙ, НАВЫКОВ
}

\section{Путренок Екатерина Леонидовна}

к.э.н., доцент,

педагог дополнительного образования Детский образовательный центр «DreamKidsClub»

\begin{abstract}
Аннотация: В рамках данной статьи представлена авторская педагогическая разработка комплексной методики подготовки к школе, в основе которой лежит игровая деятельность; интерес детей 5-6 лет к конструкторам LEGO; а также создание с помощью современных технологий двигающихся роботизированных механизмов. При этом обучающиеся легко осваивают все необходимые навыки и с удовольствием занимаются. Дети, проходя обучение по данной методике, не только учатся читать, писать и считать, но и развивают речь, получают навыки эффективной коммуникации, приучаются к самостоятельности.
\end{abstract}

Ключевые слова: робототехника, дополнительное образование, «мягкие» навыки, развитие самостоятельности у ребенка, подготовка к школе.

\section{PREPARATION FOR SCHOOL WITH ROBOTS: COMPREHENSIVE DIAGNOSTIC TECHNIQUE AND DEVELOPMENT OF THE NECESSARY KNOWLEDGE, SKILLS}

\section{Putrenok Ekaterina Leonidovna}

\begin{abstract}
Within the framework of this article, the author's pedagogical development of a comprehensive methodology for preparing for school is presented, which is based on the interest of children 5-6 years old in games with LEGO constructors, as well as the creation of moving robotic mechanisms using modern technologies. At the same time, they easily master all the necessary skills and are happy to study. Children, being trained in this method, not only learn to read, write and count, but also develop speech, gain effective communication skills, and learn to be independent.
\end{abstract}


Key words: robotics, additional education, "soft" skills, the development of independence in a child, preparation for school.

В последнее время программы подготовки к школе организованы в каждой муниципальной школе. Многие частные организации дополнительного образования и развивающие центры так же заявляют об их реализации. Зачастую в основе таких программ лежит утверждение, что для готовности к школе ребенку достаточно научиться читать, писать и считать, при этом совершенно не развиваются такие необходимые навыки, как самостоятельность, умение работать в команде и учитывать интересы других детей, работа с эмоциями. Редко развитие речи является приоритетными задачами. Кроме того, дети воспринимают такое обучение как необходимость и очень редко ходят на такие занятия с удовольствием, что значительно ухудшает запоминаемость материала.

В 2021 году на базе детского образовательного центра «DreamKidsClub» в г. Ставрополе была разработана комплексная методика «Подготовка к школе с роботами», которая решает все перечисленные выше проблемы.

Авторами данной программы являются педагог дополнительного образования Путренок Екатерина Леонидовна, педагог-психолог Пивоварова Олеся Вячеславовна, психолог Медведева Наталья Анатольевна.

Часто родители думают, что если ребёнок умеет читать и считать, то он уже способен к обучению в школе. Так ли это? Однозначно нет. Очень важно понимать, насколько малыш социализирован. Сможет ли он адаптироваться в новой среде? Есть ли у него мотивация к обучению?

Многие родители не знают ответ на этот вопрос. И в школах при реализации программ подготовки этим особенностям не уделяется внимание. Школьные учителя не производят входного тестирования и психологической диагностики, они не уделяют внимание адаптации детей в полной мере, ставя задачу пройти курс по установленной схеме. В этих курсах, как правило, предусмотрено обучение буквам, основам чтения по слогам, и написанию букв в соответствии с прописями, а также азам математических расчетов и логическим задачам. Родителям не дают ответы на такие важные вопросы, как:

1. Насколько развит у ребёнка уровень психосоциальной зрелости (кругозор знаний и навыков общения);

2. Каков уровень мотивации к обучению; 
3. Насколько развито мышление, восприятие, игровая и познавательная деятельность;

4. Эмоциональное состояние и настрой ребенка;

5. Какие у него особенности и направленность интересов;

6. Уровень самооценки ребенка.

И, как вывод, каков общий уровень подготовки к школе.

Не зная этого, родители затрудняются с выбором, на что обратить внимание и как скорректировать занятость ребенка в этот важный год - год перед школой. Наш коллектив поставил перед собой задачу: помочь родителям получить ответ на данный вопрос. Но этого недостаточно - решили мы. И пошли дальше. Мы разработали методику обучения, которая позволяет развить в ребенке все необходимые навыки, психологически его подготовить к школе. А для того, чтобы ребенок хотел заниматься, учиться писать, считать и читать в основу этой методики была положена игра с роботами LEGO.

Ни для кого не секрет, что ребенок осваивает значительно больший объем информации, когда ему действительно интересно и если знания он добывает самостоятельно. И наши занятия построены именно таким образом: играя с собственноручно собранным роботом из образовательного конструктора LEGO WEDO 2.0 ребята изучают окружающий мир, вместе с ним учат буквы, решают математические примеры и логические задачи, пишут прописи и работают с графомоторными дорожками.

Именно такой подход дает нужный результат: ребенок учится с интересом, вовлекаясь в процесс. И наши педагоги могут индивидуально корректировать задания, исходя из результатов входного и промежуточных диагностических процедур. Реализуется такая экспериментальная методика в городе Ставрополе, на базе детского образовательного центра «DreamKidsClub».

В чем же заключается суть нашей методики? Для начала, мы систематизировали информацию о необходимых знаниях и навыках, которые должен уметь применять ребенок, чтобы быть успешным в школе. Результат этой работы мы представили в таблице 1. 
Показатели готовности к школе

\begin{tabular}{|c|c|}
\hline ПОКАЗАТЕЛЬ & Краткий комментарий \\
\hline $\begin{array}{l}\text { I. Нормально } \\
\text { сформированная речь и } \\
\text { мышление }\end{array}$ & 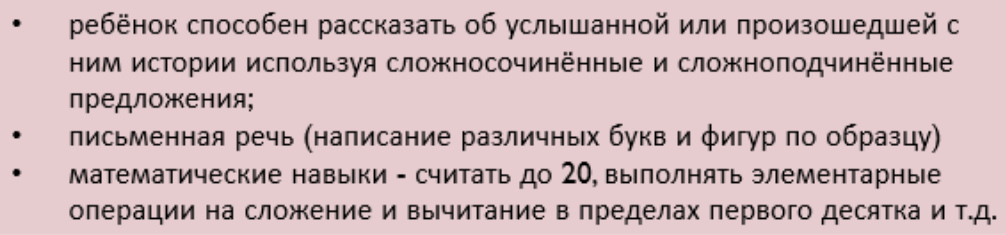 \\
\hline Восприятие & $\begin{array}{l}\text { - } \quad \text { ребёнок различает цвета, формы и контуры предметов; } \\
\text { ребёнок способен определить место нахождения предмета в } \\
\text { пространстве относительно других объектов. }\end{array}$ \\
\hline Внимание и память & $\begin{array}{l}\text { - } \quad \text { ребёнок способен длительное время удерживать внимание на } \\
\text { выполнении задания (минимум I5-25 минут); } \\
\text { ребёнок способен сравнительно быстро выучить небольшое } \\
\text { стихотворение, отрывок из текста, новые термины. }\end{array}$ \\
\hline Волевая регуляция & $\begin{array}{l}\text { · } \quad \text { ребёнок понимает, что значит слово «надо»; } \\
\text { способен выполнять указания взрослого, сидеть, внимательно слушать } \\
\text { не отвлекаясь - 20-35 минут. }\end{array}$ \\
\hline Воображение & $\begin{array}{l}\text { - это ключевой навык необходимый для развития смыслового чтения, } \\
\text { если ребёнок не способен представить прочитанного, то и любить } \\
\text { читать он не будет никогда }\end{array}$ \\
\hline $\begin{array}{l}6 . \quad \text { Знание } \\
\text { окружающего мира }\end{array}$ & $\begin{array}{l}\text { - общие знания о природе: времена года, время суток, дни недели, } \\
\text { дикие и домашние животные, базовые знания растений. }\end{array}$ \\
\hline $\begin{array}{l}7 . \text { Физическое } \\
\text { здоровье }\end{array}$ & $\begin{array}{l}\text { · выпеболок способен держать спинку прямо сидя на стуле; } \\
\text { в постой комплекс развивающей зарядки. }\end{array}$ \\
\hline
\end{tabular}

Далее мы сформулировали главный закон обучения по этой программе: голова обучающегося должна быть не только хорошо наполнена, но и хорошо устроена. То есть, все, что знает ребенок, он должен понимать и применять в жизни, а не просто формально запоминать. Ведь чем меньше «готовых» знаний получит дошкольник, чем больше сам их «откроет», тем выше будет уровень его интеллекта.

Следующим этапом стала разработка двух методик, которые должны привести к одному результату: ребенок, прошедший подготовку по этой программе должен быть готов к школе физически и психологически, а также уметь читать, писать и считать.

Первая методика - это методика психологической диагностики. Проводится три раза на протяжении года подготовки ребят. Первый раз - это входное тестирование. Задача этой стадии определить знания, умения, навыки и психологический настрой ученика «на входе». Цель - определить, на какие индивидуальные особенности обратить внимание в ходе обучения. Второе 
тестирование проводится через 4 месяца обучения. Задача - понять динамику и результат работы. Цель: сделать выводы и при необходимости скорректировать программу для каждого ученика. Третье тестирование провидится по итогам 10 месяцев обучения для подтверждения эффективности данной методики и формирования советов родителям на первый год обучения в школе.

Вторая методика - непосредственно сам процесс обучения. Мы определили, что занятия должны проводиться 2 раза в неделю в течение трех уроков по 40 минут на каждый:

1. робототехника,

2. окружающий мир и математика,

3. развитие речи, письмо, чтение.

Общее содержание каждого урока и получаемые навыки приведены на рисунках $1,2,3$.
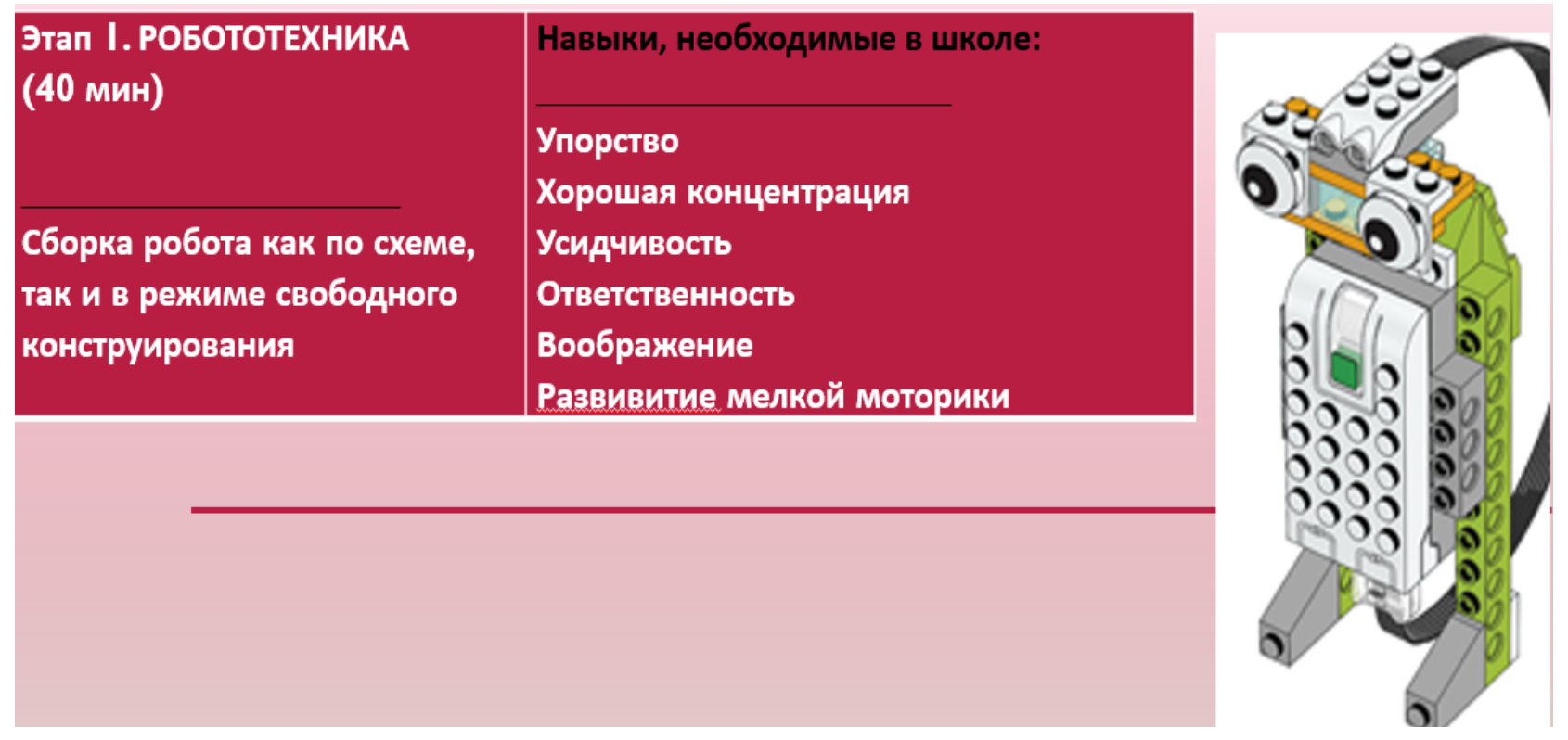

Рис. 1. Первый этап обучения. Урок робототехники

О достоинствах робототехники для развития ребенка, ее преимуществах, навыках, которые можно привить ребенку с еe использованием, можно прочитать в статье Путренок Е.Л. Здесь мы не будем на них останавливаться. 


\begin{tabular}{|c|c|}
\hline $\begin{array}{l}\text { Этап 2. Окружающий мир (20 мин) } \\
\text { Изучаем все, что связано с темой I } \\
\text { раздела }\end{array}$ & $\begin{array}{l}\text { Навыки, необходимые в школе: } \\
\text { Аналитические навыки (умение } \\
\text { сравнивать, делать выводы) } \\
\text { Хорошая концентрация } \\
\text { Развитие речи и мышления } \\
\text { Тренировка памяти }\end{array}$ \\
\hline Этап 3. Математика (20 мин) & Навыки, необходимые в школе: \\
\hline $\begin{array}{l}\text { Используя детали конструктора } \\
\text { и собранного робота, дети с } \\
\text { интересом выполняют задания }\end{array}$ & $\begin{array}{l}\text { Счет в пределах } 20, \\
\text { сложение и вычитание, } \\
\text { соотнесение цифр и реальное количество } \\
\text { предметов, } \\
\text { написание цифр, } \\
\text { решение логических задач, } \\
\text { знание геометрических форм. }\end{array}$ \\
\hline
\end{tabular}

\section{Рис. 2. Второй этап обучения. Урок «Окружающий мир и математика»}

\begin{tabular}{|c|c|}
\hline $\begin{array}{l}\text { Тренируем техническую речь. } \\
\text { В игровой форме учим термины. } \\
\text { Учимся читать. } \\
\text { И много-много говорим }\end{array}$ & $\begin{array}{l}\text { Навыки, необходимые в школе: } \\
\text { Буквы, слоги, чтение небольших текстов. } \\
\text { Составление рассказов. } \\
\text { Беседы на заданные темы. } \\
\text { Развитие воображения и фантазии у ребенка. } \\
\text { Формирование интереса к книгам, текстам и чтению. }\end{array}$ \\
\hline $\begin{array}{l}\text { Этап 5. Подготовка руки к письму. Письменная речь. (20 } \\
\text { мин) }\end{array}$ & Навыки, необходимые в школе: \\
\hline $\begin{array}{l}\text { Прописи } \\
\text { Штриховки } \\
\text { Лабиринты } \\
\text { Графомоторные дорожки } \\
\text { Написание букв и цифр }\end{array}$ & $\begin{array}{l}\text { Письменная речь } \\
\text { Правильная осанка при написании текстов } \\
\text { Правильное удержание ручки/карандаша в руке }\end{array}$ \\
\hline
\end{tabular}

\section{Рис. 3. Третий этап обучения. Урок «Родной язык и подготовка руки к письму»}

При этом в течение одного дня, то есть всех трех уроков выдерживается тематика занятия. Например, если ребята делают робота лягушку, то мы изучаем, как в природе из головастика вырастает лягушка, на ее примере 
изучаем тему из окружающего мира «Мамы и их детки», читаем про нее стихи, учим ее буквы, решаем тематические примеры и т.д. (Рисунки $4,5,6$ )

ЗАНЯТИЕ 12

Тема: Мамы и их детки: лягушка и головастик.

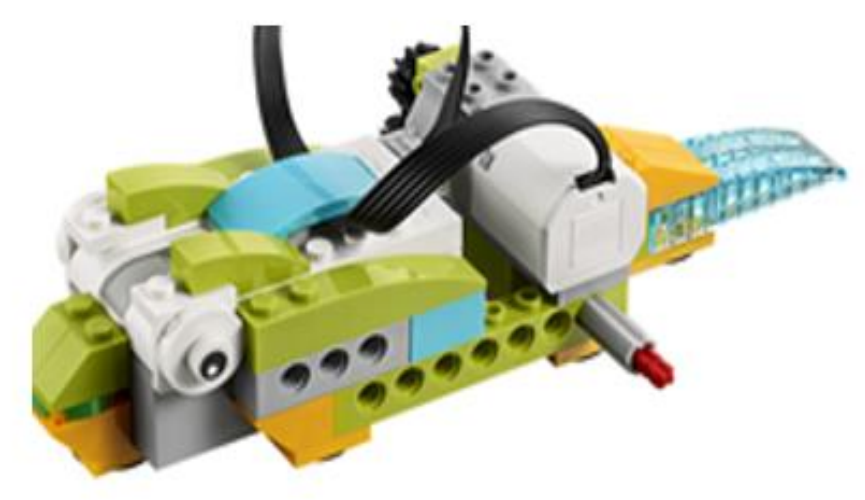

Раздел 1. Робототехника.

Сборка роботизированной модели «Лягушка»

Цель:

1. Закрепить навык сборки роботов по схеме и программирования их с использованием датчика движения.

2. Закрепить знания о прямой зубчатой передаче.

२ २акnепить наRык пnกRепения экгпепиментกR

\title{
Рис. 4. Примеры из рабочей тетради авторской программы «Подготовка к школе». Пример из урока «Робототехника»
}

Задание 2.1. (базовый уровень)

\author{
Раздел 2. Окружающий мир
}

Говорим о мамах и их детках. Обсуждаем цикл развития лягушки по картинке ниже.

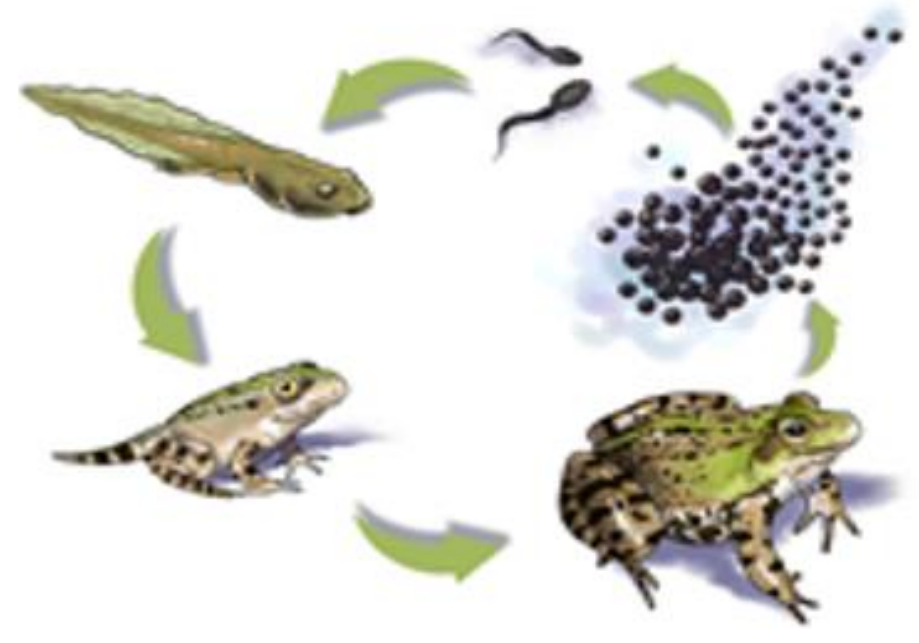

Рис. 5. Примеры из рабочей тетради авторской программы «Подготовка к школе». Пример из урока «Окружающий мир» 


\section{Раздел 3. Математика}

Цель:

1. Закрепляем навык сложения простых чисел до 7

2. Получить знания о симметрии

3. Закрепляем навык написания цифры 8

4. Учим цифру 9. Получаем навык правильного написания цифры 9

Задание 3.1. (базовый уровень).

Для лягушки мы сделали комара на уроке робототехники. Теперь у нас готов комар с 7 деталями на крылышках.

Еще раз считаем у каждого. Дети проверяют друг друга.

Задание 3.2. (базовый уровень)

Изучаем понятие симметрии - у комара крылья должны быть одинаковые. Дети проверяют друг друга.

- Сколько деталей для каждого крылышка использовали?

- Сколько деталей нужно убрать с каждой стороны, чтобы получилось 5 деталей? Запиши получившийся результат в клетки ниже.

\begin{tabular}{|l|l|l|l|l|}
\hline 7 & - & & $=$ & 5 \\
\hline
\end{tabular}

\section{Рис. 6. Примеры из рабочей тетради авторской программы «Подготовка к школе». Пример из урока «Математика»}

На рисунке 7 приведена общая схема распределения времени на протяжении всех 10 месяцев.

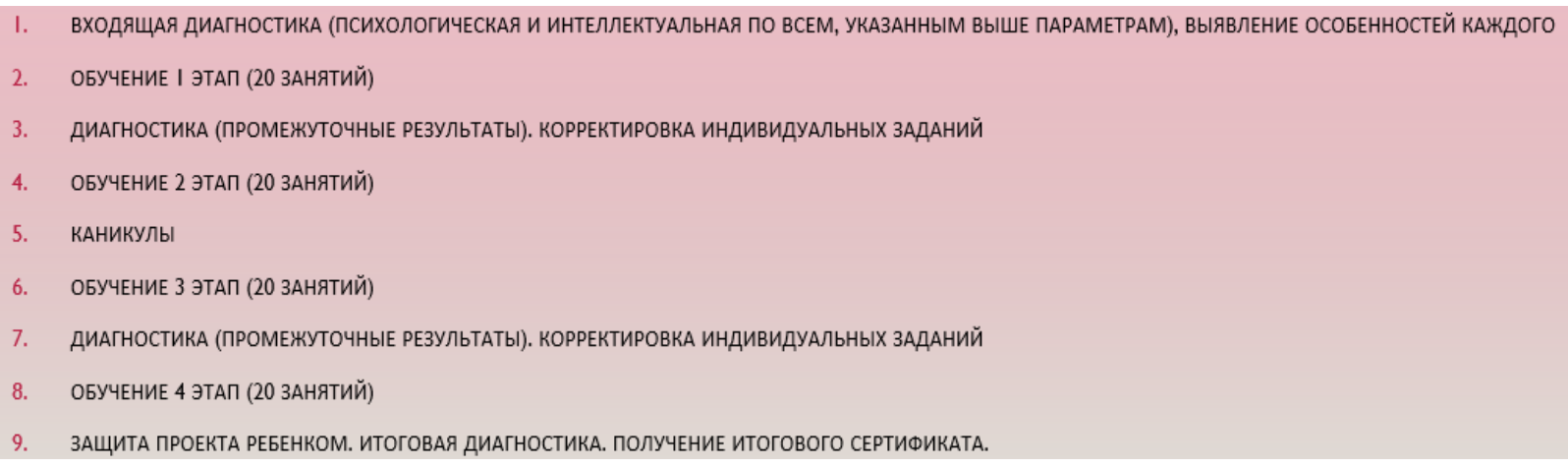

Рис. 7. Распределение времени в рамках реализации авторской методики «Подготовка к школе с роботами» 
На наших занятиях много внимания уделяется осанке и физической форме. Для этого мы внедряем игровые тематические физминутки, следим за правильной посадкой ребят во время занятия, а также используем специальные насадки на ручки, когда пишем пропись. Кроме того, в процесс включены пальчиковые игры, массажи, пальчиковая гимнастика, которые так же способствуют развитию речи ребенка.

Мы много работаем над их самостоятельностью и ответственностью за свои поступки и принимаемые решения. Например, мы с самого первого занятия договорились, что наши ученики самостоятельно собирают рюкзачки на наши уроки, и сами должны взять сменную обувь. Первое время малыши пытались сложить ответственность на мам и бабушек. Но уже сегодня они уверенно приходят к нам полностью собранные самостоятельно. И это только один из наших вполне ожидаемых результатов.

В настоящее время на базе нашего образовательного центра проводится обучение экспериментальной группы по данной методике. Результат оправдывает наши ожидания:

1. Дети с удовольствием занимаются;

2. Они стали более ответственными и самостоятельными;

3. Все более уверенно готовят рассказы с презентацией своей работы на каждом занятии;

4. Проявляют активность при получении знаний;

5. Показывают высокую скорость освоения изучаемого материала.

Данные результаты подтверждаются не только нашими педагогами, но и родителями, с отзывами которых можно ознакомиться на официальном сайте «DreamKidsClub»: https://dreamkids26.ru/.

\section{Список литературы}

1. Барышникова М. В. Влияние мелкой моторики на речевое развитие дошкольников. электронный ресурс. Доступ по ссылке: http://io.nios.ru/articles2/77/10/vliyanie-melkoy-motoriki-na-rechevoe-razvitiedoshkolnikov

2. Медведева, Н.А. Диагностика и формирование когнитивномоторных и когнитивно-интеллектуальных компонентов способностей одаренных детей и выявление их взаимосвязи. [Текст]: дис. ... канд. псих. наук: 19.00.01: защищена 2002 / Автор Медведева Наталья Анатольевна. Ставрополь., 2002. - 166 с. - Библиогр.: с.151-166. 
3. Панькова Л.А. Всё, что должен знать дошкольник при поступлении в первый класс. Серия: Готовимся к школе. - Изд-во: Литера, 2017 г.

4. Путренок Е.Л. Как заставить «шестеренки» работать: роль робототехники в развитии детей. Сборник статей всероссийского профессионально-исследовательского конкурса «Профессионал года 2020». Петрозаводск: МНЦП «Новая Наука», 2020 г., с. 8 - 15

5. Урунтаева Г. А., Афонькина Ю. А. Практикум по детской психологии. - М. "Просвещение; Владос, 1995

6. Щур В.Г. Методика «Лесенка» для дошкольников. Электронный pecypc. Доступ по ссылке: https://vip-divan.su/raznoe/metodika-lesenka-shhurdlya-doshkolnikov-metodika-lesenka-dlya-doshkolnikov.html

(C) Е.Л. Путренок, 2021 